\title{
Study on the Positioning and Strategy Selection of Rural Development in Chengdu Under the Background of Rural Revitalization
}

\author{
Xiao Hanfang ${ }^{1, a}{ }^{\text {Wu }} \mathrm{Wei}^{2}$, b* \\ ${ }^{1}$ School of Logistics, Chengdu University of Information Engineering, Longquanyi District, Chengdu, Sichuan, China \\ ${ }^{2}$ School of Logistics, Chengdu University of Information Engineering, Longquanyi District, Chengdu, Sichuan, China \\ 15609039658@163.com \\ b*596687989@qq.com
}

\section{ABSTRACT}

Since the implementation of the strategy of rural revitalization in China, the rural development has been improved, but compared with the eastern and central regions, the rural development in the western region is still lagging behind, so it is necessary to find new ideas and new directions to further accelerate the pace of rural revitalization. According to the four types of rural areas proposed in the strategic plan of rural revitalization issued by the state (2018-2022), this paper takes Chengdu as an example to carry out the corresponding rural classification analysis, further deepen the classification of rural types, subdivide the rural categories from the four angles of rural characteristics, urban-rural integration, infrastructure construction, rural function, and give the corresponding positioning basis. On this basis, combined with the successful cases of rural revitalization in Chengdu, scientific strategic suggestions are put forward for each type of rural areas.

Keywords: rural revitalization, rural positioning, policy Selection.

\section{乡村振兴背景下成都市乡村发展的定位和策略选择研 究}

肖涵方 ${ }^{1, a}$ 吴卫 ${ }^{2, b *}$

${ }^{1}$ 成都信息工程大学物流学院, 龙泉驿区, 成都, 四川, 中国

2 成都信息工程大学物流学院, 龙泉驿区, 成都, 四川, 中国

${ }^{a} 15609039658 @ 163 . c o m$

b*596687989@qq.com

摘要：我国乡村振兴战略实施以来, 乡村发展得到了改善, 但是, 相较于东部、中部地区, 西部地区乡村发 展依然滞后, 为加快西部地区乡村振兴的发展步伐, 需要细化分类, 明确各类乡村的发展定位, 从而制定与之 相匹配的发展策略。国家发布的《乡村振兴战略规划（2018-2022 年）》中提出了集聚提升类、城郊融合类、 特色保护类、搬迁撤并类四种乡村分类，本文在此基础上，对成都市的乡村类别再细分，从乡村集聚、城乡融 合、自然和文化、项目影响四个角度，进行了乡村类别的再细分，并给出了相应的定位依据，结合成都市乡村 振兴的成功案例, 针对每一类乡村类型提出与之匹配的发展策略建议。

关键词: 乡村振兴, 乡村定位, 策略选择

1. 引言

十九大报告提出实施乡村振兴战略, 2018 年国 家发布《乡村振兴战略规划（2018-2022 年）》，习 
近平总书记一系列重要讲话对我国乡村振兴的各个 方面提出了具体要求, 也为我国乡村发展指明了方 向。相较于东部、中部地区, 西部地区乡村发展依然 滞后, 需要寻找新思路新方向来进一步加快实现西部 地区乡村振兴的步伐。学者们针对乡村振兴发展也进 行了探索和研究, 但多是针对某一类型乡村发展给出 策略建议, 缺乏对整个乡村发展的系统研究, 研究点 较为分散, 尤其缺乏对我国乡村振兴的一些重要的基 础性问题，如功能定位、特点、分类等进行研究。从 而导致对乡村振兴发展的研究和实际操作缺乏基础 支撑, 本文将尝试在一定程度上弥补这方面的不足。 ${ }^{[1]}$ 成都作为我国西部的重要城市, 本文选取对成都市 域内的乡村作为研究对象, 拟通过乡村功能性分类, 乡村定位发展给出匹配的乡村发展策略选择的建议, 以促进成都市乡村振兴的速度和效率, 也能在西部地 区起到良好的示范和引领作用。 ${ }^{[2]}$

\section{2. 乡村发展定位的意义}

在乡村振兴战略的大背景下, 要想实现乡村振兴 预期目标, 需要采取一系列与当地乡村实际相适应的 政策措施。中央农办、农业农村部发布的 “关于统筹 推进村庄规划工作的意见” 提到要合理划分县域村庄 类型, 对村庄人口变化、区位条件、发展特点进行研 究, 明确可以将村庄基本分为集聚提升类村庄、城郊 融合类村庄、特色保护类村庄、搬迁撤并类村庄四类。 便于统筹谋划村庄发展。成都市乡村开展分类定位的 较少, 乡村分类定位的标准也各不相同, 如何制定更 科学的分类标准? 不同类别的乡村怎样准确找到适 宜的振兴发展策略? 需要考虑到多个层面的因素。乡 村定位标准的应用, 有针对性地选择发展策略, 在成 都市实现乡村经济高速发展具有重大的意义, 不仅可 以为后续乡村振兴打下基础, 也能为乡村创新创业提 供保障。 ${ }^{[3]}$

\section{3. 乡村振兴战略下成都市乡村类别再细分与 定位}

\section{1. 研究区概况}

成都市是四川省省会, 地处成都平原, 在四川盆 地西部, 地势由西北向东南倾斜, 总体地势平坦, 河 网分布多, 物产丰富、农业发达, 属于亚热带季风性 湿润气候, 年平均气温 16 摄氏度, 年降雨量 1000 毫 米左右, 水资源总量 101.87 亿立方米, 总量丰富, 但人均量少。地理位置介于东经 $102^{\circ} 54^{\prime}-104^{\circ}$ $53^{\prime}$, 北纬 $30^{\circ} 05^{\prime}-31^{\circ} 26^{\prime}$ 之间。现辖有 12 区 3 县 5 市, 2019 年成都市常住人口 1658.1 万人, 农村人口为 424.31 万人，占成都市人口 $74.41 \%$ ，第 一产业总产值 1003.3 亿元。

\section{2. 乡村类型的划分依据}

《乡村振兴战略规划（2018-2022 年）》提出我
国乡村类别可以划分为四类，分别是集聚提升类乡 村、城郊融合类乡村、特色保护类乡村、搬迁撤并类 乡村。我国幅员面积辽阔, 地形气候等情况多样化, 对于每一个地区需要有更为详细的乡村类别划分标 准, 形成一种推广面较大的科学的乡村划分方法。

\section{2. 1. 集聚提升类乡村}

首要目的是为了整合多方资源, 实现经济实力最 大化。一类以经济发展较强的行政村, 发挥龙头作用, 将周边距离较近, 乡村环境特点相似的乡村融为一个 整体, 以点带面, 实力强的村带动实力相对较弱的村, 促进乡村地区以 “面” 提升自身的经济实力。一类是 以地区性特点, 以中心地区交通条件相对较完善的乡 村为主, 串联周边边远乡村、规模较小的乡村、实力 较弱的乡村, 形成区域性乡村网络结构, 联动多乡村 联合发展。

\subsection{2.城郊融合类}

乡村距离城镇较近, 可以在发展中享受到城镇发 达的交通等基础设施带来的便利, 更快地融入到城镇 建设中, 加快实现乡村城镇化, 提高城镇化率, 改善 乡村经济发展面貌。此类乡村符合城乡融合的条件, 不具有其他类型乡村的特点, 可以承接城镇产业链和 配套企业, 为优化城镇建设分担空间压力, 也能逐步 纳入城乡发展统一规划中, 实现乡村经济的发展。

\section{2. 3. 特色保护类乡村}

概念较为宽泛, 可以依据我国特色乡村收录名单 加以确认，如传统文化乡村、少数民族特色乡村、特 色自然景观乡村等。蕴含着丰富的历史文化, 还具有 独特的文化景观气息, 可以利用本村的特色优势, 进 行开发利用。除此之外, 能够被当地认定为特色文化 乡村的, 同样应当纳入保护, 在得到妥善保护的前提 下, 开发利用, 提振此类乡村经济。 ${ }^{[5]}$

\section{2. 4. 搬迁撤并类乡村}

主要有生态环境较为恶劣、人口流失严重、自然 灾害多发、因重大工程项目需要搬迁的乡村地区，这 类乡村普遍经济发展滞后, 需要易地扶贫搬迁, 这都 需要以当地政府部门进行科学界定为准。在一些特殊 情况下, 需要搬迁撤并的乡村也应该纳入此类乡村名 单中。

\section{3. 成都市乡村类别的再细分和定位依据}

依据《乡村振兴战略规划（2018-2022 年）》提 出的我国乡村基本类别, 但是, 不同地区存在着不一 样的乡村发展情况，就算同一类别中相适应的乡村发 展策略也会有所不同, 因此必须基于成都市乡村的实 际情况, 再细分乡村的发展类别, 以符合成都市乡村 
的特点, 明确乡村发展具体定位, 并给出相匹配的策 略建议。在四类基本类别下，以成都市交通便利、乡 村发展较快、城乡融合较好等特点, 对四类中每一类 别进行再细化分类, 集聚提升类乡村 (A) 再细化为 龙头集聚型 (A1)、偏远型（A2）、交通优势型（A3）、 其他特殊情况 (A4) 四小类; 城郊融合类乡村 (B) 再细化为城镇郊区型（B1）、城镇驻地型（B2）、其 他特殊情况（B3）三小类; 特色保护类乡村 (C) 再 细化为自然景观乡村 (C1)、中华文化乡村 (C2)、 农业特色品牌乡村 (C3) 三小类; 搬迁撤并类乡村 (D) 再细化为土地整合类（D1）、重大项目型乡村 (D2) 两小类。一共 12 小类。乡村的定位再细分和细分依 据见表 1 所示:

表 1 乡村的细分类别和依据

\begin{tabular}{|c|c|c|}
\hline $\begin{array}{l}\text { 乡村 } \\
\text { 类别 }\end{array}$ & $\begin{array}{l}\text { 乡村类别 } \\
\text { 再细分 }\end{array}$ & 定位依据 \\
\hline \multirow{4}{*}{$\begin{array}{l}\text { 集聚 } \\
\text { 提升 } \\
\text { 类乡 } \\
\text { 村 }(\mathrm{A})\end{array}$} & $\begin{array}{l}\text { 龙头集聚 } \\
\text { 型乡村 } \\
\text { (A1) }\end{array}$ & $\begin{array}{l}\text { 在一定区域内, 存在经济发展 } \\
\text { 较好, 有龙头产业带动, 乡村 } \\
\text { 区域优势明显 }\end{array}$ \\
\hline & $\begin{array}{l}\text { 偏远型乡 } \\
\text { 村 (A2) }\end{array}$ & $\begin{array}{l}\text { 分布在周边乡村稀少、地理位 } \\
\text { 置距离乡镇较远、地势较高交 } \\
\text { 通不便的地方 }\end{array}$ \\
\hline & $\begin{array}{l}\text { 交通优势 } \\
\text { 型乡村 } \\
\text { (A3) }\end{array}$ & $\begin{array}{l}\text { 相对于周边乡村而言, 处于交 } \\
\text { 通网络较为密集, 与主干道或 } \\
\text { 次干道距离较近, 具有交通枢 } \\
\text { 纽特点的乡村 }\end{array}$ \\
\hline & $\begin{array}{l}\text { 其它情况 } \\
\text { (A4) }\end{array}$ & $\begin{array}{l}\text { 乡村发展基本稳定, 不具有较 } \\
\text { 大的独特发展潜力, 可以与周 } \\
\text { 边形成集聚的乡村 }\end{array}$ \\
\hline \multirow{3}{*}{$\begin{array}{l}\text { 城郊 } \\
\text { 融合 } \\
\text { 类乡 } \\
\text { 村 }(B)\end{array}$} & $\begin{array}{l}\text { 城镇郊区 } \\
\text { 型乡村 } \\
\text { (B1) }\end{array}$ & $\begin{array}{l}\text { 地理位置处在城乡结合部的乡 } \\
\text { 村, 属于城镇郊区、待发展或 } \\
\text { 处于远期规划区域 }\end{array}$ \\
\hline & $\begin{array}{l}\text { 城镇驻地 } \\
\text { 型乡村 } \\
\text { (B2) }\end{array}$ & $\begin{array}{l}\text { 位于城镇城区范围内的乡村社 } \\
\text { 区 }\end{array}$ \\
\hline & $\begin{array}{l}\text { 其他情况 } \\
\text { (B3) }\end{array}$ & 具备与城镇融合发展的乡村 \\
\hline \multirow{3}{*}{$\begin{array}{l}\text { 特色 } \\
\text { 保护 } \\
\text { 类乡 } \\
\text { 村 }(\mathrm{C})\end{array}$} & $\begin{array}{l}\text { 自然景观 } \\
\text { 乡村 (C1) }\end{array}$ & $\begin{array}{c}\text { 收录到 “全国美丽乡村” “全 } \\
\text { 国特色景观名村” 中的乡村 }\end{array}$ \\
\hline & $\begin{array}{l}\text { 中华文化 } \\
\text { 乡村 (C2) }\end{array}$ & $\begin{array}{c}\text { 收录到 “中国传统村落名录” } \\
\text { 中的乡村 }\end{array}$ \\
\hline & $\begin{array}{l}\text { 农业特色 } \\
\text { 品牌乡村 } \\
\text { (C3) }\end{array}$ & $\begin{array}{c}\text { 收录到 “一村一品” “全国特 } \\
\text { 色村庄” 中的乡村 }\end{array}$ \\
\hline \multirow{2}{*}{$\begin{array}{c}\text { 搬迁 } \\
\text { 撤并 } \\
\text { 类乡 } \\
\text { 村 (D) }\end{array}$} & $\begin{array}{l}\text { 土地整合 } \\
\text { 类 (D1) }\end{array}$ & $\begin{array}{l}\text { 因项目实施需要, 需要对乡村 } \\
\text { 土地进行重新整合, 统筹规划。 }\end{array}$ \\
\hline & $\begin{array}{l}\text { 重大项目 } \\
\text { 型乡村 } \\
\text { (D2) }\end{array}$ & $\begin{array}{c}\text { 因实施重大工程项目，导致乡 } \\
\text { 村范围和布局发生改变 }\end{array}$ \\
\hline
\end{tabular}

\section{4. 基于乡村再细分类别的成都市乡村定位}

基于《乡村振兴战略规划（2018-2022 年）》提 出我国乡村类别可以划分为四类。以成都市域乡村的 基本情况进行二级细化分类, 构建了乡村分类概念模 型。尽可能地能够涵盖成都市所有乡村。在进行乡村 归类时, 通过图 1 (乡村分类模型) 分别对应, 判断 出乡村类别, 为后续策略的对应选择提供依据。

其中，在这 12 小类的乡村类别中，符合 A1 的有 暆都区新民场镇下辖的多个乡村, 这些乡村都有苗木 龙头企业和农业发展公司来带动当地经济的发展; $\mathrm{A} 2$ 有简阳市老龙村, 地处偏远, 需要科学探寻发展方法; A3 有青白江区城厢镇十八湾村, 地处交通要道, 且

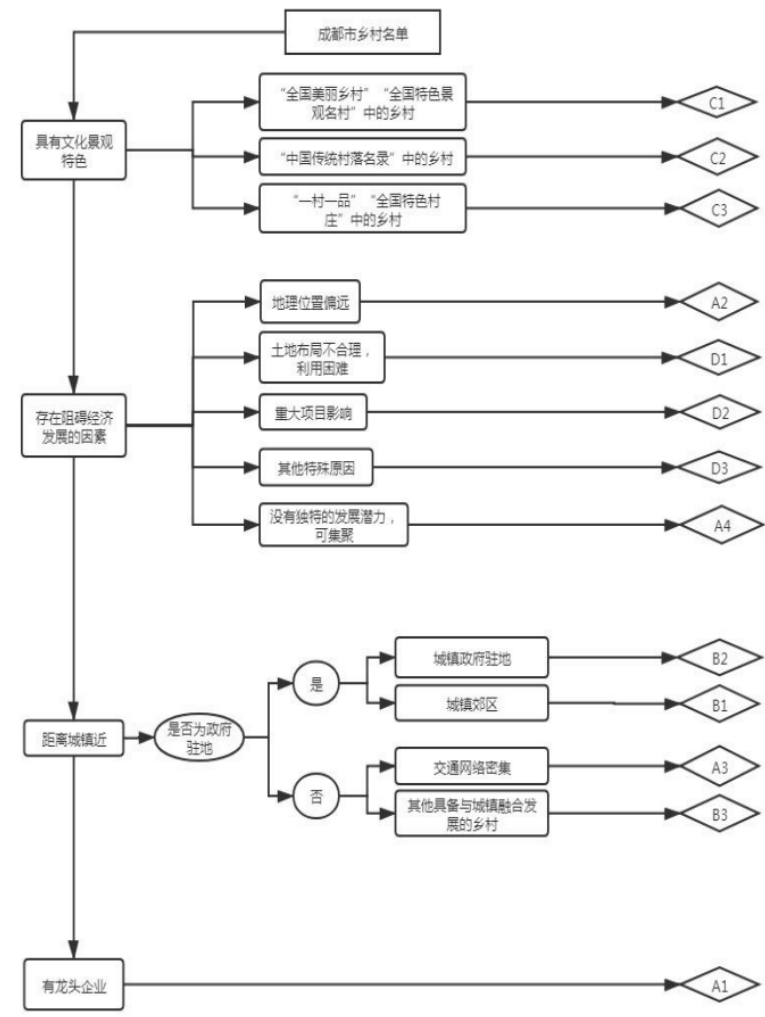

图 1 乡村分类模型

距离高速出口较近; A4 主要针对于不具有 A 类 其他小类乡村特点, 但可以与周边乡村形成集聚效应 的乡村。B1 有温江区岷江村、天星村, 距离周边一 个或多个城市较近，具有城镇郊区的特征。B2 有龙 泉驿区大面街道下辖师大社区和龙安社区, 地处城镇 社区政府驻地, 有着区位优势。B3 主要针对不处于 郊区, 不是政府驻地, 但距离城市很近, 可以与城市 发展相融合的乡村, 需要特殊考虑。C1 有大邑县西 岭镇下辖 6 个行政村, 地处风景区内或周边, 能够依 靠着风景区发展。C2 有青白江区光明村, 有过街莲 萧、板発龙非物质文化遗产，蒲江县仙阁村有飞山腰 鼓、寒山染坊非物质文化遗产。具有中华传统文化特 征。C3 有新都区农和村, 凭借传统的面粉产业, 创 立特色品牌 “北峰面粉” 提高品牌效应。D1 有温江 
区和盛镇下辖乡村, 整理土地, 合理规划, 发展田园 综合体。D2 有郈都区西华街道下辖社区，因新建大 学、高速等重大项目, 使得村社区进行重新规划建设。

由于成都市村社区数量较大, 本文对每一小类进 行举例证明, 为后续成都市提供乡村分类方法, 使各 个乡村社区在制定发展策略之前, 能为乡村进行精确 定位。

\section{4. 基于再细分类别的成都市乡村发展策略建 议}

\section{1. 集聚提升类}

\section{1. 1. 龙头集聚型}

郫都区新民场镇下辖的多个乡村在成都市现代 苗木科技公司的带动下, 针对多种植株进行栽培, 形 成独具一派的 “川派” 造型植株。成都市花中花农业 公司在新津区宝墩村建设种植专业合作社, 作为公司 粮食稻谷产品和食用油产品的供应基地。

此类乡村在龙头企业的优势推动下, 利用本村土 地集中生产, 既发挥了土地效益, 也提升了村民的就 业率，在龙头企业扩大生产的情况下，本村可联合邻 近和村落情况类似的乡村, 形成龙头企业集聚型乡 村, 让周边乡村也乘上龙头企业的快车, 以一个村的 龙头企业, 辐射到一片地区的乡村, 满足龙头企业扩 大生产的需要, 也实现了更多邻近和类似情况的乡 村, 提速乡村振兴, 实现了互利共赢。

\section{1. 2. 偏远型}

简阳市老龙村，地处偏远，没有特色产业，没有 地区优势, 通过老龙乡招商引资, 在下辖包括老龙村 在内的多个乡村, 实现抱团振兴, 集中发展有机农产 品种植, 形成多家蔬菜水果合作社, 改善了偏远地区 乡村发展情况。

此类乡村要在合作抱团的基础上，首先完善当地 交通等基础设施的建设, 为招商引资, 抱团致富提供 前提条件, 偏远型乡村多为所属乡镇偏远, 下辖多个 乡村也就都存在着地处偏远, 得不到有效发展的情 况, 因此, 抱团形成联合体是关键, 统一多方面的政 策, 能在招商中显示出更强的吸引力和竞争力, 统一 的价格, 统一的承包期限和规则, 能为相关企业的进 驻减少很多的阻碍。

\section{1. 3. 交通优势型}

青白江区城厢镇十八湾村地处成都第二绕城高 速旁, 周边多条大道相连, 形成了村道乡道城市主干 道和高速的紧密相连, 为十八湾村特色食用菌产业园 区的建设发挥了巨大的作用, 原料和成品运输都能方 便快捷的进出成都市，节省了距离和时间。
此类乡村多处于交通要道、交通枢纽、交通网络 密集区附近，拥有得天独厚的交通优势，可联合周边 同样具有交通优势的其他乡村或者邻近但不具有相 同优势的乡村，打通交通连接线，将优势主村落与周 边乡村紧密相连，提升周边乡村的交通优势，使企业 愿意进驻, 当地农产品能够快速到达市场, 为合作社 和创新产业的出现提供基础。

\section{1. 4. 其他情况}

成都市存在着以上情况都不具有的乡村, 但依然 能够与周边有事乡村进行集聚的特点, 需要考虑到此 类乡村的集聚发展。

\section{2. 城郊融合类}

\section{2. 1. 城镇郊区型}

温江区怅江村、天星村等村落, 地处温江区城区 周围, 距离城区很近, 依靠城区人口多, 日常休闲娱 乐的契机，整合本村土地资源，集中连片开发，依托 温江区北林绿道沿线, 进行生态旅游开发, 打造田园 生态综合体项目、休闲观光项目, 吸引城区人口转移 到本村休闲娱乐, 创造经济收入, 扩大乡村旅游影响 力。

此类乡村距离城区较近，市场大，可探寻城市中 没有的自然风光项目, 为城区人口提供闲㗇时光休闲 娱乐的去处，打造本村特点的，例如：桂花休闲村、 民俗手工艺村、田园酒店等项目。既能够优化本村人 居生态环境, 也能够提振乡村经济和区域影响力, 吸 引更多游客。 ${ }^{[7]}$

\subsection{2. 城镇驻地型}

龙泉驿区大面街道下辖师大社区和龙安社区, 积 极营造社区环境, 加强人居环境治理工作, 强化在大 面街道区域内的中心地位, 并积极拓展公司企业的入 驻, 丰富社区娱乐生活, 增强社区在市场竞争中的实 力。

此类乡村社区处于城镇中，拥有良好的发展环 境, 需要在人居环境治理上积极创新, 在治理中显特 色，在特色治理的基础上谋发展，积极引进农业产业 链, 吸纳周边乡村人力资源和原材料, 提高城镇化率 和整体综合实力。 ${ }^{88}$

\section{2. 3. 其他情况}

在靠近城镇的乡村中, 存在着既不属于郊区, 也 不属于政府驻地的乡村社区, 但是, 依然具有与城镇 融合发展的特点, 需要针对此类情况特殊处理。 


\section{3. 特色保护类}

\section{3. 1. 自然景观类}

大邑县西岭镇下辖 6 个行政村, 位于西岭雪山风 景区及附近, 海拔较高, 但具有独特的自然景观, 全 镇村村通公路，依靠自然资源，发展乡村旅游业。在 深化旅游行业的过程中，不断强化基础设施的建设, 优化风景区及沿线环境，打造出良好的景区口碑。

此类乡村可依托自然资源，包括自然风光、生态 农产品和配套服务业的开发, 在保护好资源的前提 下, 从多方面挖掘自然资源, 为乡村经济的提振创造 动力。

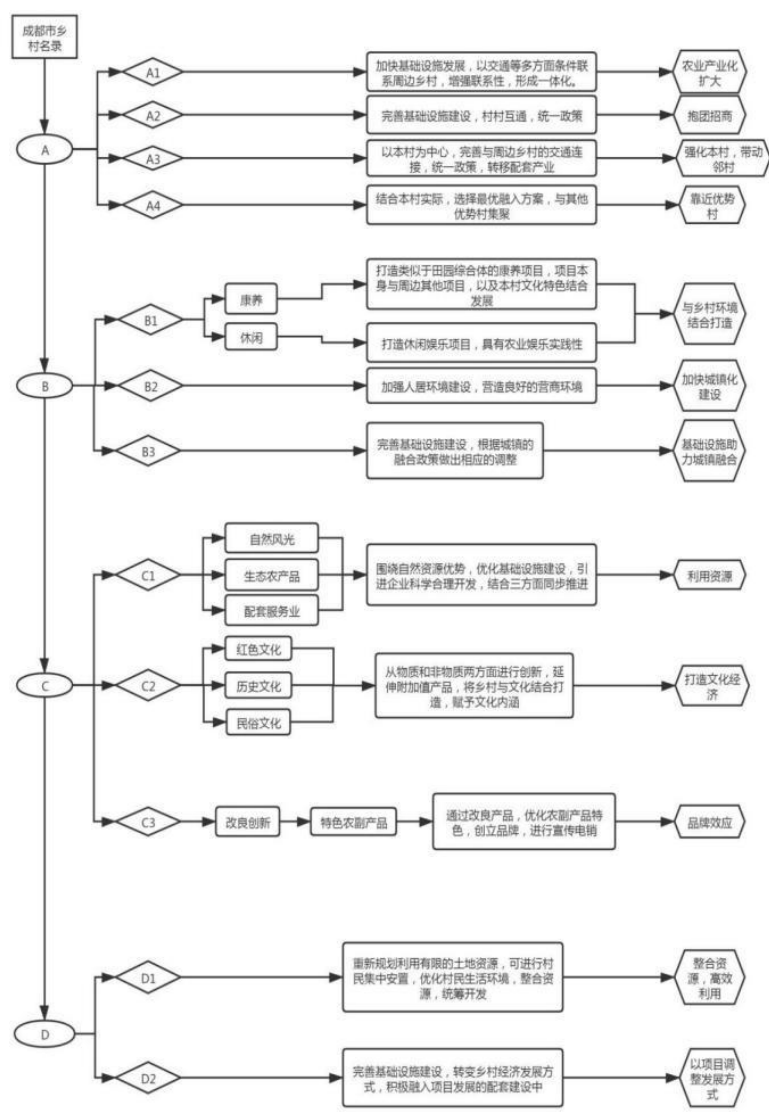

图 2 乡村策略选择模型

\subsection{2. 中华文化类}

青白江区光明村有过街莲萧、板登龙非物质文化 遗产, 蒲江县仙阁村有飞山腰鼓、寒山染坊非物质文 化遗产, 这些乡村积极保护传统技艺, 申报非物质文 化遗产，宣传本村遗产特色，组建相应的非物质文化 队伍, 加强本村文化遗产影响力, 吸引游客前来感受 文化的鬼米力。

这类乡村应当抓住文化遗产的传统性和传承性, 由于现代生活中已经较少能够了解到此类文化特色, 要更好发挥文化遗产的鬼米, 需要从物质和非物质双 重创新, 延伸出附加值产品, 增强文化遗产吸引力,
按照文化特色整体打造本村落，与现代技艺相融合， 在乡村生活气息中处处体现，赋予本村文化印记。

\subsection{3. 农业特色品牌类}

新都区农和村在面粉发展上起步较早，已经形成 了一条较为先进的生产线, 并成立了自己的品牌 “北 峰面粉”, 该公司生产能力强, 有着较大的种植基地, 带动了当地村民的就业，并始终坚持产地质量把关， 营造了良好的市场环境。

此类乡村有着自身的农产品特色, 例如: 香梨、 富硒西瓜、豆腐等农产品, 挖掘本村产品的独特点, 在此基础上, 开发新的吸引点, 创立自己的品牌, 放 大特色农产品的影响力，增强市场竞争能力，增加收 益。

\section{4. 搬迁撤并类}

\section{4. 1. 土地整合类}

温江区和盛田园综合体项目的实施, 需要整合大 量土地资源，但又面临着民居分散面大，不易利用土 地的问题, 因此, 开展了土地整合, 重新合理规划使 用土地，集中开发田园综合体项目，实现经济收益。

此类乡村由于民居和土地划分等原因, 导致项目 实施过程中会面临很多问题，为了提振乡村经济，尽 快落地落地落实乡村振兴项目, 就需要统筹规划, 建 立村民集中安置区，重新布置土地使用方式，高效发 挥土地利用价值。

\section{4. 2. 重大项目开发类}

鄎都区西华街道下辖社区，因大学建设、高速高 铁建设等重大项目，对原多个村落进行了整合，部分 民居搬迁，顺利实施重大项目建设。

此类乡村在项目实施的影响下, 乡村格局和环境 发生较大的改变, 与此同时, 发展类型也由传统农业 耕作转变为城镇服务业等相关配套服务上, 这类乡村 应抓住城镇融合机会, 围绕项目开展新的乡村项目, 创造收益。

\section{5. 结论}

(1) 在乡村振兴战略的大背景下, 要想实现乡 村振兴预期目标, 需要采取一系列与当地乡村实际相 适应的政策措施。本研究立足于四川省成都市域内, 通过对成都市不同地域的乡村特点进行分析, 准确定 位出几类乡村类型，为后续政策措施的制定做好前 提, 进行针对性的措施实施, 实现乡村振兴的预期目 标。现如今, 对成都市乡村开展分类定位的较少, 乡 村分类定位的标准也各不相同，如何制定更科学的分 类标准，不同类别的乡村怎样准确找到适宜的振兴发 展策略, 至关重要。通过进一步细化乡村类型分类, 
形成了乡村定位 4 大类 12 小类的乡村类别划分体系, 明确了针对不同乡村的定位识别方法，构建了分类模 型, 以及每一类乡村所对应的策略选择模型。

（2）在构建基本乡村定位的分析中，主要考虑 成都市乡村的实际发展情况, 进行了类别特征的确 定, 由于成都市乡村社区数量多, 本文以举例的方式, 对构建的乡村定位模型中的每一类做出参照, 未全部 分类。另一方面, 部分乡村存在各种特殊情况, 在参 照本文提出的乡村分类模型和策略选择模型时, 同样 需要根据本村的特殊情况加以调整, 不能完全照搬。

\section{REFERENCES}

[1] Liu Yansui and Zang Yuzhu and Yang Yuanyuan.(2020)China's rural revitalization and development: Theory, technology and management[J]. Journal of Geographical Sciences,30(12):1923-1942.

[2] Zhou L.(2018)Research on the core mechanism and industrial integration of rural revitalization[J].Administrative Reform,(8): 33-38.

[3] Zhang H.(2018)The mode selection and realization mechanism of rural entrepreneurship to promote rural revitalization[J].Journal of Jishou University (Social Science Edition),39(3): 92-98.

[4] Chen X, Cheng C.(2018)The route of three industries integration under the strategy of rural revitalization: logical inevitability and empirical judge[J].Issues in Agricultural Economy,(11): 91-100.

[5] Shen Jing and Chou RungJiun.(2021) Cultural Landscape Development Integrated with Rural Revitalization:A Case Study of Songkou Ancient Town[J]. Land,10(4):406-406.

[6] Wen T, Yang Z, Zhang J.(2018)The way to realize the industrial prosperity in the rural revitalization strategy[J].Administrative Reform,(8): 26-32.

[7] Yang Guo.(2021)Research on the Planning and Design of Leisure Agriculture Industrial Park under the Background of Rural Revitalization[J]. Journal of Physics:Conference Series, 1865(3)1-5.

[8] Chen Mingxing et al.(2021)The Integration of New-Type Urbanization and Rural Revitalization Strategies in China: Origin, Reality and Future Trends[J]. Land,10(2):207-207.

[9] Yang Jun et al.(2021)Effects of rural revitalization on rural tourism[J].Journal of Hospitality and Tourism Management, 47 : 35-45.

[10] Kan Karita.(2021)Creating land markets for rural revitalization: Land transfer, property rights and gentrification in China[J].Journal of Rural
Studies,81: 68-77. 